\title{
Nonthermal plasma assisted photocatalytic oxidation of dilute benzene
}

\author{
J KARUPPIAH ${ }^{\mathrm{a}, \mathrm{b}}$, E LINGA REDDY ${ }^{\mathrm{a}, \mathrm{b}}$, L SIVACHANDIRAN ${ }^{\mathrm{a}, \mathrm{b}}$, R KARVEMBU ${ }^{\mathrm{a}}$ and \\ Ch SUBRAHMANYAM ${ }^{\mathrm{b}, *}$ \\ ${ }^{a}$ Department of Chemistry, National Institute of Technology, Tiruchirappalli 620 015, India \\ ${ }^{b}$ Department of Chemistry, Indian Institute of Technology, Hyderabad 502 205, India \\ e-mail: csubbu@iith.ac.in
}

MS received 1 December 2011; revised 17 February 2012; accepted 8 March 2012

\begin{abstract}
Oxidative decomposition of low concentrations (50-1000 ppm) of diluted benzene in air was carried out in a nonthermal plasma (NTP) dielectric barrier discharge (DBD) reactor with the inner electrode made up of stainless steel fibres (SMF) modified with transition metal oxides in such a way to integrate the catalyst in discharge zone. Typical results indicate the better performance of $\mathrm{MnO}_{\mathrm{x}}$ and $\mathrm{TiO}_{2} / \mathrm{MnO}_{\mathrm{x}}$ modified systems, which may be attributed to the in situ decomposition of ozone on the surface of $\mathrm{MnO}_{\mathrm{x}}$ that may lead to the formation of atomic oxygen; whereas ultraviolet light induced photocatalytic oxidation may be taking place with $\mathrm{TiO}_{2}$ modified systems. Water vapour improved the selectivity to total oxidation.
\end{abstract}

Keywords. Nonthermal plasma; sintered metal fibres; photocatalysis; ozone decomposition; VOC abatement.

\section{Introduction}

Advanced oxidation processes (AOPs) have been receiving great attention for the removal of various air and water bound pollutants. ${ }^{1-3}$ AOPs, in general, mineralize the pollutants through generation of powerful oxidizing agents like atomic oxygen, hydroxyl radical, $\mathrm{H}_{2} \mathrm{O}_{2}$ etc. ${ }^{4-6}$ Photocatalytic oxidation of organic compounds using $\mathrm{TiO}_{2}$ may present many advantages like the ease of operation, especially during the mineralization of water bound organic pollutants like dyes, etc. and it has been reported to be very efficient for both decolorization and degradation of various pollutants. ${ }^{7-9}$ However, all these techniques have limited success during the oxidation of air pollutants. In this context nonthermal plasma (NTP) generated by electrical discharges under ambient conditions have specific advantages in terms of mild operating conditions and may generate strong oxidizing agents like ozone, hydroxyl radical, etc. Hence proper positioning of catalyst is warranted as many of these species are short-lived. NTP-catalytic oxidation has been studied extensively for decomposition of various pollutants, including volatile organic compounds (VOCs). ${ }^{10-22}$ It has been reported that with a combination of catalyst, it is possible to overcome the limitations of NTP, especially low selectivity to total oxidation. NTP in air produces ultraviolet (UV) radiation due to excited nitrogen

*For correspondence molecules. ${ }^{23}$ However, earlier attempts to promote UV induced oxidation were not promising, probably due to the low intensity of UV light. It is recently reported that by proper modification of the electrodes, it is possible to utilize the UV light for photocatalytic decomposition of chlorinated VOCs. ${ }^{23}$

Benzene, a commonly used industrial solvent, whose abatement under dilute concentrations $(<1000 \mathrm{ppm})$ may not be economical by conventional techniques. The present study was aimed at the total oxidation of dilute benzene in a DBD reactor. The inner electrode of the DBD rector was made of sintered metal fibres (SMF) which were suitably modified with either a photocatalyst $\mathrm{TiO}_{2}$ and/or $\mathrm{MnO}_{\mathrm{x}}$. In addition, the present study highlights the role of UV light in improving the performance of the combined plasma catalytic technique due to synergy effect.

\section{Experimental}

The details of DBD reactor and SMF modification with $\mathrm{TiO}_{2}, \mathrm{MnO}_{\mathrm{x}}$ and $\mathrm{TiO}_{2} / \mathrm{MnO}_{\mathrm{x}}$ was reported elsewhere. ${ }^{24,25}$ Briefly, $\mathrm{TiO}_{2} / \mathrm{SMF}$ was prepared by the precipitation of Ti-(IV) bis (ammonium lactato) dihydroxide, $50-\mathrm{wt} \%$ solution in water at $333 \mathrm{~K}$ for $3 \mathrm{~h}$, whereas, $\mathrm{MnO}_{\mathrm{x}}$ was deposited by impregnation. ${ }^{26}$ Drying at room temperature followed by calcination in air at $773 \mathrm{~K}$ for $5 \mathrm{~h}$ resulted metal oxide supported SMF 
catalysts. Finally, SMF filters were shaped into a cylindrical form. Discharge length was $10 \mathrm{~cm}$ and discharge gap was $3.5 \mathrm{~mm}$. The desired specific input energy (SIE at 230 or $260 \mathrm{~J} / \mathrm{l}$ ) was applied by varying the AC high voltage. The V-Q Lissajous method was used to determine the discharge power (W) from which SIE was calculated. Benzene (50 to $1000 \mathrm{ppm}$ ) diluted in air was fed into the reactor $(0.51 / \mathrm{min} \mathrm{STP})$, whose concentration at the outlet was measured with a gas chromatograph (Varian 450), whereas an infrared $\mathrm{CO}_{\mathrm{x}}$ analyzer (AIC, India) was used to monitor the $\mathrm{CO}$ and $\mathrm{CO}_{2}$ formed. Ozone concentration was measured with an UV absorption detector (API-450 NEMA). The catalytic electrodes were characterized as reported earlier. ${ }^{23}$ As the influence of ultraviolet light may be expected only if NTP emits radiation with $\lambda \leq 370-380 \mathrm{~nm}$, which is equivalent to the band gap of anatase $(3.2 \mathrm{eV})$, emission spectrum of the discharge in the wavelength range $250-500 \mathrm{~nm}$ was reported in our earlier publication. ${ }^{23}$

\section{Results and discussion}

Activity of the modified catalytic SMF electrodes was tested at a specific input energy (SIE) of $230 \mathrm{~J} / 1$ as a function of benzene concentration varied between 50 and $1000 \mathrm{ppm}$ and the results are presented in figure $1 \mathrm{a}$. As seen from the figure 1a, conversion of benzene increases with decreasing benzene concentration and among the catalysts studied, unmodified SMF showed the lowest activity, probably due to the lack of catalyst component. This is further supported by better conversion over transition metal modified SMF electrodes. For example, for $1000 \mathrm{ppm}$ of benzene, $\mathrm{TiO}_{2} / \mathrm{SMF}$ showed slightly higher conversion to that of SMF and $\mathrm{TiO}_{2} / \mathrm{MnO}_{\mathrm{x}} / \mathrm{SMF}$ showed the best conversion of $65 \%$ compared to $50 \%$ on SMF electrode. It is worth mentioning that $\mathrm{TiO}_{2} / \mathrm{MnO}_{\mathrm{x}} / \mathrm{SMF}$ demands energy $1.6 \times$ $10^{5} \mathrm{~J} / \mathrm{mol}$. However, decreasing benzene concentration increased the conversion over the entire range of catalysts including unmodified SMF. This increase is significant when SMF is modified with $\mathrm{MnO}_{\mathrm{x}}$, which may be due to the formation of a strong oxidizing agent, atomic oxygen by in situ decomposition of ozone, as reported earlier. ${ }^{26}$ Interesting observation is that SMF modified with both $\mathrm{MnO}_{\mathrm{x}}$ and $\mathrm{TiO}_{2}$ showed highest activity for any concentration. For example, for $50 \mathrm{ppm}$ of benzene the activity of the catalytic electrodes followed the order $\mathrm{SMF}<\mathrm{TiO}_{2} / \mathrm{SMF}<\mathrm{MnO}_{\mathrm{x}} / \mathrm{SMF}<\mathrm{TiO}_{2} / \mathrm{MnO}_{\mathrm{x}} / \mathrm{SMF}$ and $\mathrm{TiO}_{2} / \mathrm{MnO}_{\mathrm{x}} / \mathrm{SMF}$ showed $\sim 100 \%$ conversion at $230 \mathrm{~J} / 1$. It is worth mentioning that the conventional methods for the removal of VOCs may not be effective under such lower concentrations due to the non-adiabatic conditions. ${ }^{20,23,24}$
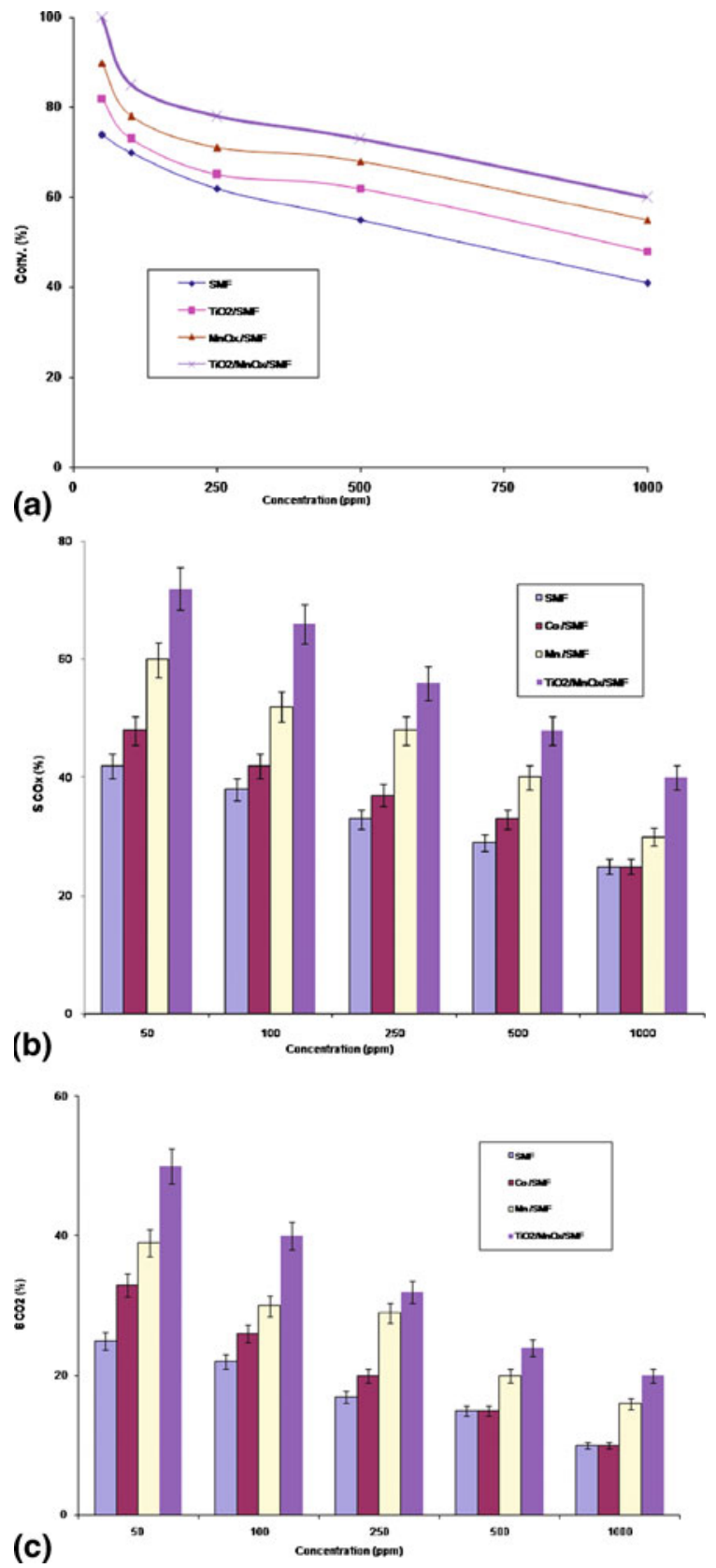

Figure 1. Influene of SMF modification and benzene concentration on (a) conversion, (b) selectivity to $\mathrm{CO}_{\mathrm{x}}$ and (c) selectivity to $\mathrm{CO}_{2}$ at $230 \mathrm{~J} / 1$.

During the destruction of VOCs, the desired is total oxidation, i.e., $\mathrm{CO}_{2}$ and $\mathrm{H}_{2} \mathrm{O}$, however, NTP destruction of VOCs is non-selective and may lead to the undesired polymeric deposit in addition to $\mathrm{CO}$ and $\mathrm{CO}_{2}$, and hence elimination of carbonaceous deposit is warranted. Figure $1 \mathrm{~b}$ presents the selectivity to gaseous products $\left(\mathrm{CO}\right.$ and $\left.\mathrm{CO}_{2}\right)$. As these are the only gaseous products observed, $\mathrm{S}_{\mathrm{COx}}$ may also present the carbon 
balance of the present reaction. Interesting observation is that at $230 \mathrm{~J} / 1$, decreasing concentration of benzene increased the selectivity to gaseous products. As seen from figure $1 \mathrm{~b}$, SMF electrode at $50 \mathrm{ppm}$ showed $40 \% \mathrm{~S}_{\mathrm{COx}}$ against $25 \%$ for $1000 \mathrm{ppm}$. SMF modification with transition metal oxides also increased the selectivity. $\mathrm{TiO}_{2} / \mathrm{SMF}$ showed slightly higher selectivity than unmodified SMF, whereas $\mathrm{MnO}_{\mathrm{x}}$ and $\mathrm{TiO}_{2} / \mathrm{MnO}_{\mathrm{x}} / \mathrm{SMF}$ showed still higher activity. For $50 \mathrm{ppm}$ of benzene, $\mathrm{TiO}_{2} / \mathrm{MnO}_{\mathrm{x}} / \mathrm{SMF}$ showed around $80 \% \quad \mathrm{~S}_{\mathrm{COx}}$ against $40 \%$ on $\mathrm{SMF} . \mathrm{CO}_{2}$ selectivity also followed the same trend where $\mathrm{TiO}_{2}$ modified electrodes showed better activity as presented in figure 1c. For $50 \mathrm{ppm}$ of benzene, SMF showed $\sim 25 \%$ selectivity to $\mathrm{CO}_{2}$ against $50 \%$ with $\mathrm{TiO}_{2} / \mathrm{MnO}_{\mathrm{x}} / \mathrm{SMF}$. For any electrode, $\mathrm{S}_{\mathrm{CO} 2}$ decreased significantly with increasing concentration. For example, during the oxidation of $1000 \mathrm{ppm}$ of benzene, $\mathrm{TiO}_{2} / \mathrm{MnO}_{\mathrm{x}} / \mathrm{SMF}$ showed only $25 \%$ selectivity.

The better performance of $\mathrm{TiO}_{2}$ modified systems may be either due to surface activation of $\mathrm{TiO}_{2}$ by thermal activation, ozone decomposition and/or UV initiated photo catalytic oxidation. In order to ensure the role of $\mathrm{TiO}_{2}$, ozone concentration at the outlet of the reactor was measured. At $260 \mathrm{~J} / 1$, with SMF and $\mathrm{TiO}_{2} / \mathrm{SMF}$, formation of $350 \mathrm{ppm}$ of ozone was observed, whereas, $\mathrm{MnO}_{\mathrm{x}}$ and $\mathrm{TiO}_{2} / \mathrm{MnO}_{\mathrm{x}} / \mathrm{SMF}$ produced $\sim 0 \mathrm{ppm}$. It clearly indicates that the improvement observed with $\mathrm{MnO}_{\mathrm{x}} / \mathrm{SMF}$ may be due to in situ decomposition of ozone that may lead to the formation of strong oxidant atomic oxygen, whereas, $\mathrm{TiO}_{2}$ modified electrodes are not effective for decomposition of ozone. Thermal activation of $\mathrm{TiO}_{2}$ catalyst in general requires a temperature in the range 573 to $673 \mathrm{~K}$, whereas, during the present study, the outlet gas temperature never exceeded $\sim 303 \mathrm{~K}$. Hence, it may be concluded that the DBD reactor with catalytic electrode showed higher activity due to synergy between ozone decomposition and photocatalytic action.

In order to ensure the observation that $\mathrm{TiO}_{2}$ modified electrodes increased the performance of the DBD plasma reactor, benzene conversion was followed at $260 \mathrm{~J} / 1$ in the concentration range $50-1000 \mathrm{ppm}$ and data was presented in figure 2 . As seen from the figure $2 \mathrm{a}, \mathrm{SMF}$ electrodes followed the same trend as observed earlier.

As the time scales of the reactions taking place in plasma are very small and catalyst may also deactivate due to the solid carbonaceous deposits on the walls of the reactor, long-term performance of the DBD reactor is much warranted. Figure 3, presents the performance of the DBD reactor over a period of time at SIE of $260 \mathrm{~J} / 1$ during the destruction of $1000 \mathrm{ppm}$ of benzene. As seen from the figure 3, all the catalytic
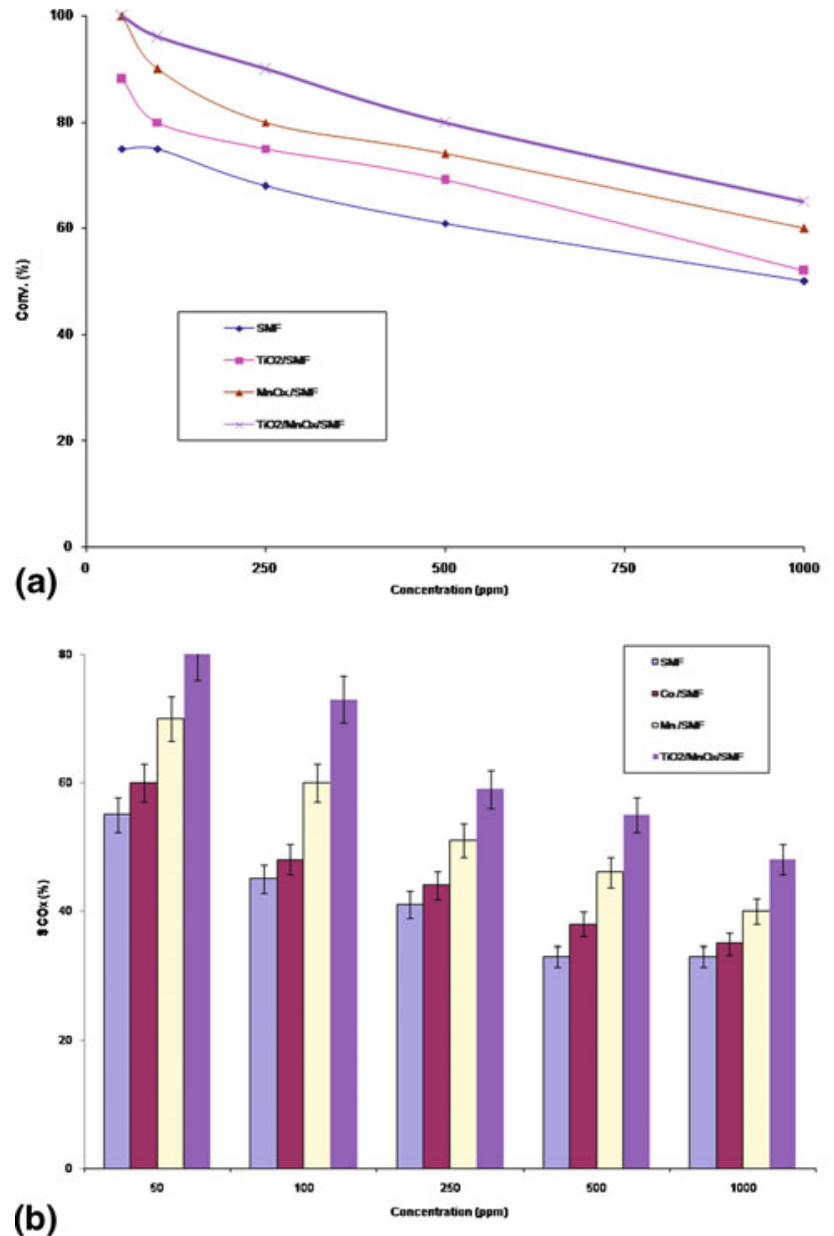

(b)

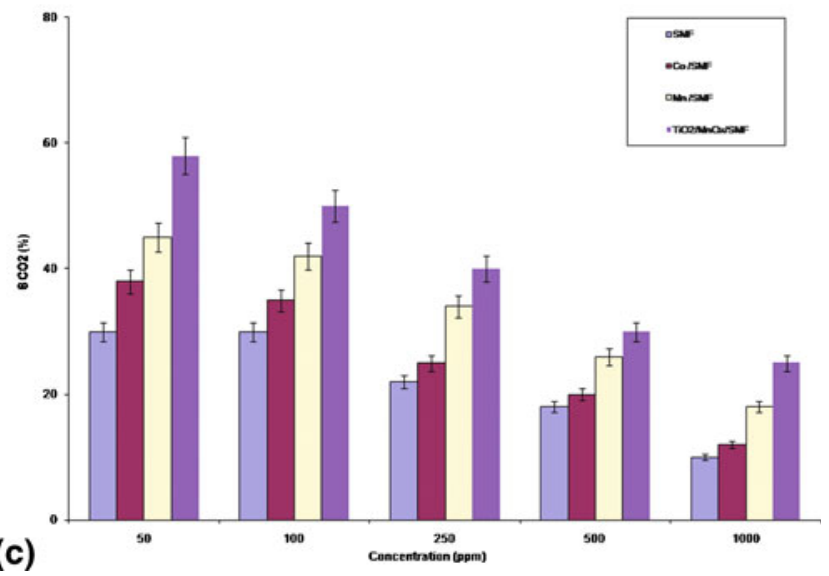

Figure 2. Influene of SMF modification and benzene concentration on (a) conversion, (b) selectivity to $\mathrm{CO}_{\mathrm{x}}$ and (c) selectivity to $\mathrm{CO}_{2}$ at $260 \mathrm{~J} / 1$.

electrodes maintain nearly the same activity throughout the course of the reaction. This may be due to the fact that in the present study, as the SMF electrode was used the high voltage electrode, where the microdischarges originate and reach the ground electrode, the carbonaceous deposit may be taking place only on the ground 


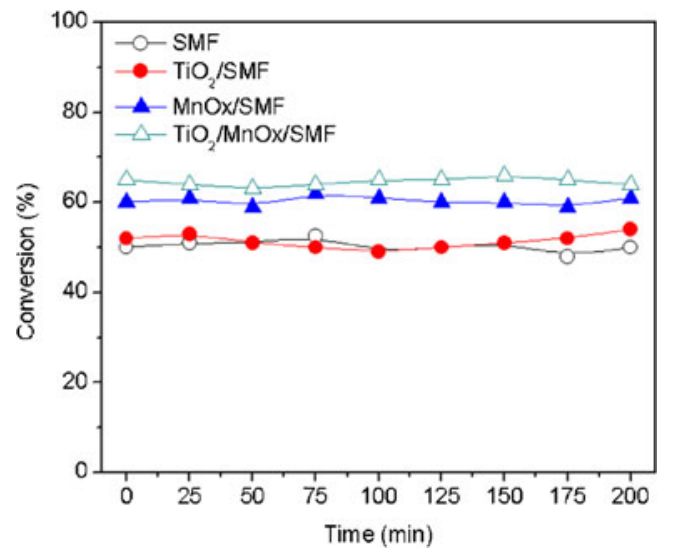

Figure 3. Conversion of $1000 \mathrm{ppm}$ of benzene as a function of time at $230 \mathrm{~J} / 1$.

electrode, hence activity of SMF electrodes remains nearly the same.

\subsection{Influence of specific input energy (SIE) on the destruction of 100 ppm of benzene over catalytic SMF electrodes}

Conversion of $100 \mathrm{ppm}$ of benzene was studied as a function of SIE variation between 170 and $320 \mathrm{~J} / 1$ and the results are presented in figure $4 \mathrm{a}$. As seen in figure $4 \mathrm{a}$, the benzene conversion increases with the increasing SIE. However, at a particular SIE, metal oxide supported SMF electrodes showed higher conversion compared to SMF unmodified electrode. For example, at $320 \mathrm{~J} / 1, \mathrm{SMF}$ electrode showed $80 \%$ conversion of benzene, whereas $\mathrm{TiO}_{2} / \mathrm{MnO}_{\mathrm{x}} / \mathrm{SMF}$ and $\mathrm{MnO}_{\mathrm{x}} / \mathrm{SMF}$ showed $\sim 90 \%$ conversion even at $290 \mathrm{~J} / \mathrm{l}$. The better performance of $\mathrm{MnO}_{\mathrm{x}} / \mathrm{SMF}$ and $\mathrm{TiO}_{2} / \mathrm{MnO}_{\mathrm{x}} / \mathrm{SMF}$ may be due to the formation of active oxygen species on metal oxide surface by the in situ decomposition of ozone. Figure $4 \mathrm{~b}$ presents the selectivity to $\mathrm{CO}_{\mathrm{x}}$ and $\mathrm{CO}_{2}$ formed in the above reaction. As seen, metal oxide supported SMF showed $\sim 75 \% \mathrm{CO}_{\mathrm{x}}$ selectivity at SIE of $290 \mathrm{~J} / 1$, whereas, with SMF this was achieved only at $320 \mathrm{~J} / \mathrm{l}$. Figure $4 \mathrm{~b}$ also represents the selectivity to $\mathrm{CO}_{2}$, which also followed the same trend as conversion and $\mathrm{CO}_{\mathrm{x}}$ selectivity. At any $\mathrm{SIE}, \mathrm{TiO}_{2} / \mathrm{MnO}_{\mathrm{x}} / \mathrm{SMF}$ electrode showed higher $\mathrm{CO}_{2}$ selectivity than $\mathrm{MnO}_{\mathrm{x}} / \mathrm{SMF}, \mathrm{TiO}_{2} /$ SMF and unmodified SMF. During the present study, at SIE of $320 \mathrm{~J} / 1, \sim 65 \% \mathrm{CO}_{2}$ selectivity was achieved with $\mathrm{TiO}_{2} / \mathrm{MnO}_{\mathrm{x}} / \mathrm{SMF}$.

\subsection{Influence of water vapour and catalyst on the decomposition of benzene}

The effect of humidity is of great interest for practical applications in industry since process gas consists of ambient air that usually contains water vapour at fluctuating concentration. Water vapour plays an important role in the plasma chemistry since it may lead to the formation of $\mathrm{OH}$ radicals. ${ }^{27,28}$ The oxidation power of $\mathrm{OH}$ is higher than other oxidants like oxygen atoms and peroxyl radicals generated in NTP. For that purpose, air containing benzene stream was bubbled through water maintained at a constant temperature $(298 \mathrm{~K})$ that corresponds to $\sim 3 \%$ of water vapour.

Oxidation of $100 \mathrm{ppm}$ of benzene in both dry and humid condition at SIE $260 \mathrm{~J} / 1$ over $\mathrm{MnO}_{\mathrm{x}} / \mathrm{SMF}$ electrode was tested. It has been observed that conversion improved in humid air when compared to dry conditions. With $\mathrm{MnO}_{\mathrm{x}} / \mathrm{SMF}$ under dry conditions conversion was only $85 \%$ whereas, on humidifying the gas
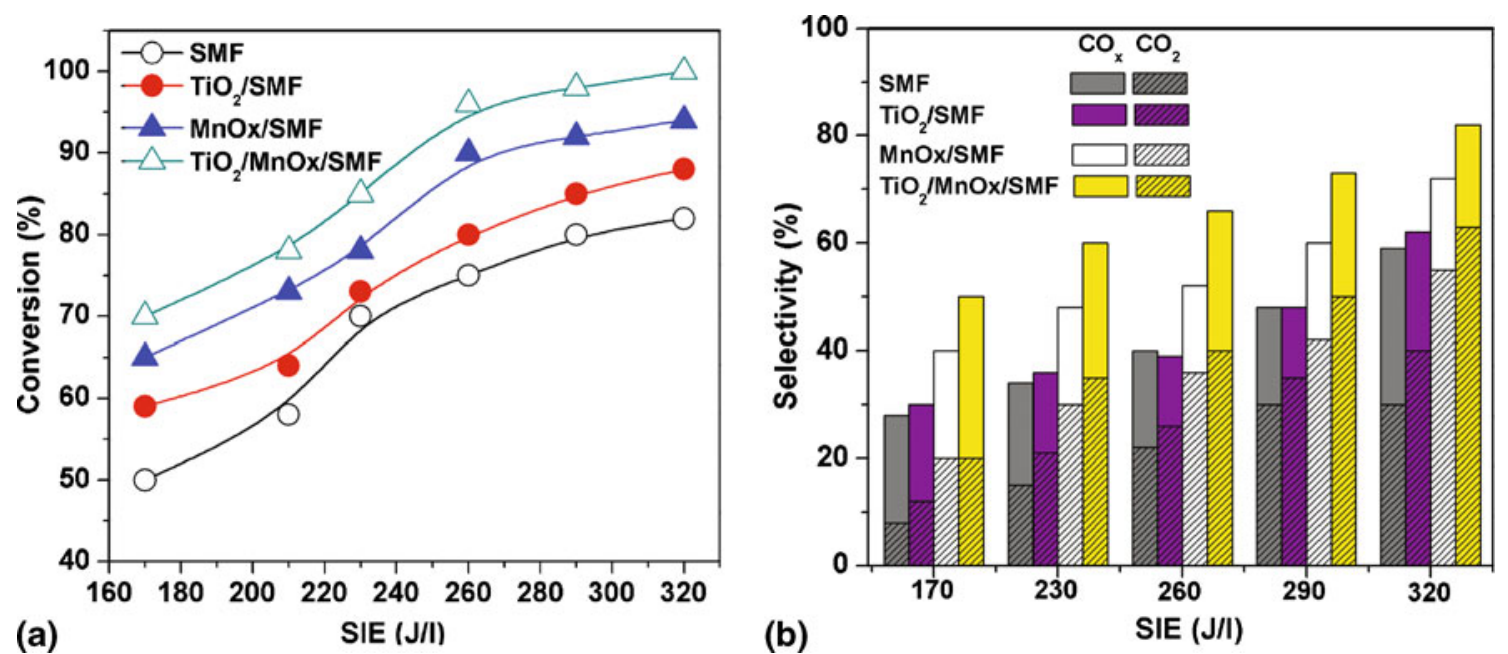

Figure 4. Influence of specific input energy on (a) conversion and (b) selectivity to the gas products (100 ppm of benzene). 
stream, conversion increased to $100 \%$. Another interesting observation is that $\mathrm{MnO}_{\mathrm{x}} / \mathrm{SMF}$ under dry condition showed only $60 \%$ selectivity to $\mathrm{CO}_{x}$, which was improved up to $90 \%$ under humid condition. The selectivity to $\mathrm{CO}_{2}$ also followed the same trend. Such a difference between dry and wet air condition may be explained by formation of $\mathrm{OH}$ radicals in the humid conditions that may lead to high selectivity to total oxidation. ${ }^{27,28}$

However, the presence of water vapour decreases the ozone concentration. During the present study, with $\mathrm{MnO}_{\mathrm{x}} / \mathrm{SMF}$, in dry air $350 \mathrm{ppm}$ of ozone was observed at $260 \mathrm{~J} / 1$ that decreased to $75 \mathrm{ppm}$ on humidification. However, water vapour decreased the formation of $\mathrm{CO}$ and enhanced the selectivity towards $\mathrm{CO}_{2} \cdot{ }^{29,30}$ Therefore, it may be reasonable to assume the presence of humidity even though decreases the ozone formation; it improves the selectivity to total oxidation.

As seen from the data presented above, SMF modified with both $\mathrm{TiO}_{2}$ and $\mathrm{MnO}_{\mathrm{x}}$ showed improved activity. Over the surface of this bimodal catalyst $\mathrm{TiO}_{2} / \mathrm{MnO}_{\mathrm{x}} / \mathrm{SMF}, \mathrm{TiO}_{2}$ and $\mathrm{MnO}_{\mathrm{x}}$ exhibit different activities, namely ozone decomposition, photocatalysis and plasma activation of oxygen atoms on catalyst surface. In the absence of thermal activation, the catalytic activity of $\mathrm{TiO}_{2}$ in NTP may be due to the photocatalysis due to UV light generated in plasma. The synergy between plasma excitation of the VOC molecules and their catalytic oxidation was further enhanced by photocatalysis, since $\mathrm{TiO}_{2}$ absorbs the UV light produced by the NTP. As seen from the figures 1 and 2, the SMF modified with $\mathrm{MnO}_{2}$ and $\mathrm{TiO}_{2}$ is able to oxidize dilute benzene, which is otherwise difficult with the conventional thermo-catalytic techniques.

\section{Conclusions}

Abatement of low concentration of benzene was studied in a DBD plasma reactor, where the inner SMF electrode was modified with transition metal oxides. Typical results highlighted the better performance of $\mathrm{TiO}_{2} / \mathrm{MnO}_{\mathrm{x}}$ supported SMF, which may be assigned due to the formation of atomic oxygen on the surface of $\mathrm{MnO}_{\mathrm{x}}$ by in situ decomposition of ozone; whereas ultraviolet light induced photocatalytic oxidation on $\mathrm{TiO}_{2}$ surface may further promote the oxidation.

\section{Acknowledgements}

Authors would like to thank the Department of Science and Technology (DST), India, for the financial support under DST-SERC project.

\section{References}

1. Forbes T H and McManus A C 1996 28th Mid-Atlantic industrial and hazardous waste conference, Buffalo NY

2. Hoffmann M R, Martin S T, Choi W and Bahnemann D W 1995 Chem. Rev. 6995

3. Herrmann J M 1999 Catal. Today 53115

4. Brant F R and Cannon F S 1966 J. Environ. Sci. Health 312409

5. Demeestere K, Dewulf J and Langenhove H V 2007 Crit. Rev. Environ. Sci. Technol. 37489

6. Evgenidou E, Konstantinou I, Fytianos K, Poulios I and Albanis T 2007 Catal. Today $\mathbf{1 2 4} 156$

7. Shen Y S, Young K U 1999 Chemosphere 381855

8. Chen W R, Sharpless C M, Linden K G, Suffet I H (Mel) 2006 Environ. Sci. Technol. 402734

9. Alberici R M, Jardim W F 1997 Appl. Catal. B: Environmental 1455

10. John Zink Company 1991 International symposium on environmental control of combustion processes. Honolulu

11. Penetrante B M, Brusasco R M, Merritt B T and Vogtlin G E 1999 Pure Appl. Chem. 711829

12. Roland U, Holzer F and Kopinke F D 2002 Catal. Today 73315

13. Futamura S, Zhang A, Prieto G and Yamamoto T 1998 IEEE Trans. Ind. Appl. 34967

14. Kim H H, Oh S M, Ogata A and Futamura S 2005 Appl. Catal. B: Environmental 56213

15. Ayrault C, Barrault J, Blin-simiand N, Jorand F, Pasquiers S, Rousseau A and Tatibouet J M 2004 Catal. Today $\mathbf{8 9} 75$

16. Eliasson B and Kogelschatz U 1991 IEEE Trans. Ind. Appl. 191063

17. Zhang K, Eliasson B and Kogelschatz U 2002 Ind. Eng. Chem. Res. 411462

18. Kogelschatz U 2003 Plasma Chem. Plasma Proc. 231

19. Holzer F, Roland U and Kopinke F D 2002 Appl. Catal. B: Environmental 38163

20. Roland U, Holzer F and Kopinke F D 2005 Appl. Catal. B: Environmental 58217

21. Gallardo-amores J M, Armaroli T, Ramis G, Finocchio E and Busca G 1999 Appl. Catal. B: Environmental 22249

22. Falkenstein Z J 1997 Adv. Oxid. Technol. 2223

23. Subrahmanyam Ch, Mangureanu M, Laub D, Renken A and Kiwi-Minsker L 2007 J. Phys. Chem C 1114315

24. Subrahmanyam Ch, Renken A and Kiwi-Minsker L 2006 Appl. Catal. B: Environmental 65150

25. Subrahmanyam Ch, Renken A and Kiwi-Minsker L 2006 Appl. Catal. B: Environmental 65157

26. Kim H H, Lee Y H, Ogata A and Futamura S 2003 Catal. Commun. 4347

27. Einaga H, Teraoka Y and Ogat A 2011 Catal. Today 164 571

28. Ogata A, Shintani N, Yamanouchi K, Mizuno K, Kushiyama S and Yamamoto T 2000 Plasma Chem. Plasma Proc. 20453

29. Karuppiah J, Karvembu R and Subrahmanyam Ch 2012 Chem. Eng. J. 18039

30. Zhu T, Li J, Jin Y, Liang $\mathrm{Y}$ and Ma G 2008 Int. J. Environ. Sci. Tech. 5375 